\title{
The diagnosis of prostatitis: a review
}

\author{
R N Thin
}

\section{Introduction}

Prostatitis is frequently regarded as an obscure illunderstood condition. This is due to a number of factors; the organ is deeply placed and poorly accessible to clinical examination, the aetiology is frequently unclear, the criteria for the diagnosis of some forms of prostatitis are not agreed, many cases of prostatitis have no distinguishing clinical features, investigation is difficult, and therapy may be time consuming and unsatisfactory. Recent studies have done much to clarify some of these issues. Different types of prostatitis have been recognised as summarised in table 1 . This review will concentrate on the common types which are usually due to infection. Infecting organisms can reach the prostate by four routes: ascending from the urethra, descending from the bladder, via the bloodstream, and via the lymphatics. As clinical features are frequently unhelpful diagnosis depends on results of special investigations. Before reviewing these anatomy and pathogenesis must be considered.

\section{Anatomy and pathogenesis}

Anatomy The prostate consists of acini draining into ducts which in turn drain into the prostatic urethra; these are set in a stroma of collagen and muscle tissue. The gland can be divided into a small central zone around the prostatic urethra, and a larger peripheral zone forming about $75 \%$ of the parenchyme of the gland. An important difference between the zones is shown in fig 1 . The ducts draining the central zone enter the prostatic urethra at an acute angle compared with the ducts draining the peripheral zone. Urine can enter the peripheral zone ducts more easily than the central zone ducts. ${ }^{1}$ Furthermore contraction of the internal sphincter muscle will tend to compress the ducts of the central zone rather than those of the peripheral zone. During ejaculation when the internal sphincter is contracted the intraurethral pressure rises dramatically and semen will enter the peripheral zone ducts more readily than the central zone ducts. Figure 2 supports this view, showing that the inflammatory process

St Thomas' Hospital and St Peters Hospitals, London

R N Thin affects the peripheral zone; the inflammatory cell exudate and small abscesses are concentrated in the peripheral zone and the central zone around the urethra is relatively unaffected. Figure 2 also illustrates the focal nature of prostatitis.

Pathogenesis Urinary reflux into the prostate may be common. Prostatic ultrasound studies indicate that prostatic calculi are frequently seen in adult men. ${ }^{2} \mathrm{On}$ analysis prostatic calculi contain constituents that occur in urine but not in prostatic secretion. ${ }^{34}$ In an elegant experiment, Kirby et al showed direct evidence of reflux into the prostate. ${ }^{5}$ Carbon particles instilled into the bladder via a catheter immediately before operation were found in the prostatic ducts of seven of ten men who had prostatic surgery. Each of five men with non-bacterial prostatitis had numerous macrophages containing carbon particles in their expressed prostatic secretion obtained by massage three days after instillation into the bladder. These findings show that reflux from urethra into the prostatic ducts can occur.

\section{Diagnosis of acute prostatitis}

Acute prostatitis is rare in Britain and in the western hemisphere, and can be readily diagnosed from its clinical features. ${ }^{6}$ There is an acute onset with malaise, fever and sometimes rigors; urinary symp-

\section{Table 1 Classification of prostatitis}

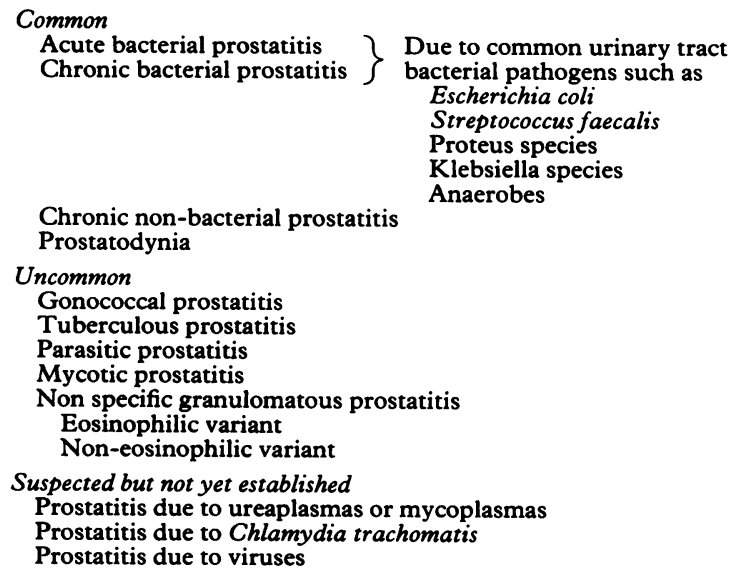

Acute bacterial prostatitis \} Due to common urinary tract Chronic bacterial prostatitis $\}$ bacterial pathogens such as Escherichia coli Streptococcus faecalis Proteus species Klebsiella species

Chronic non-bacterial prostatitis Anaerobes

Prostatodynia

Uncommon

Gonococcal prostatitis

Tuberculous prostatitis

Parasitic prostatitis

Mycotic prostatitis

Non specific granulomatous prostatitis

Eosinophilic variant

Non-eosinophilic variant

Suspected but not yet established

Prostatitis due to ureaplasmas or mycoplasmas

Prostatitis due to Chlamydia trachomatis

Prostatitis due to viruses

(After Meares, ${ }^{14}$ Drach et al, ${ }^{15}$ ) 


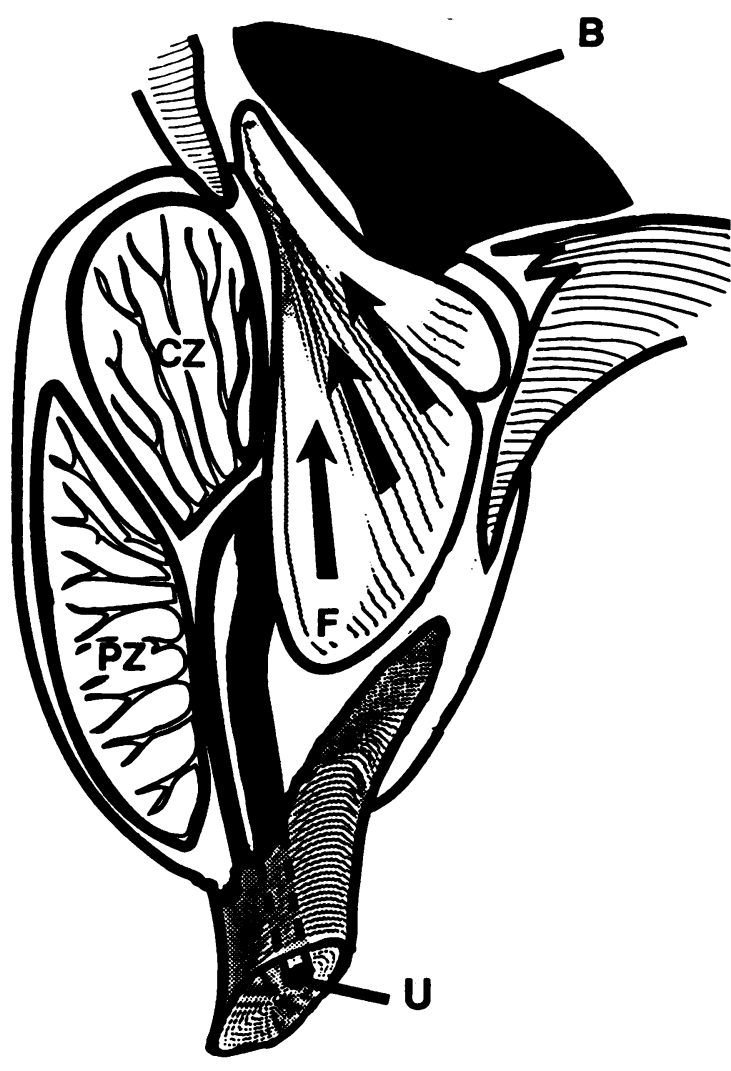

Figure 1 Semi-diagrammatic view of a sagittal section of the prostate illustrating the ducts draining the central and peripheral zones entering the urethra.

$B$ Bladder

CZ Central zone

$F \quad$ Internal sphincter

PZ Peripheral zone

U Urethra

(After Blacklock')

toms may coincide or follow, and include marked frequency, dysuria, urgency and sometimes haematuria. In addition there is usually perineal discomfort, rectal pain, low backache and tenesmus. On rectal examination the prostate is swollen and generally acutely tender. Urine culture produces a heavy growth of a urinary pathogen.

\section{Diagnosis of chronic prostatitis}

Clinical features In contrast, chronic prostatitis is common in the west but produces no distinctive constellation of clinical features. Symptoms of all forms of chronic prostatitis may include frequency of micturition, nocturia, urgency, dysuria, perineal ache, penile tip pain and low backache. Perineal ache and penile tip pain, especially occurring with or just after ejaculation indicate prostatitis, but all these symptoms are frequently absent. ${ }^{78}$ Recurrent bac- teruria with fever, malaise, and perhaps haematuria indicate chronic bacterial prostatitis. Rectal examination is frequently unhelpful. Definite localised tenderness indicates prostatitis, perhaps with abscess formation. Mild general tenderness is difficult to interpret and frequently merely indicates anxiety or intolerance of the examination. ${ }^{8}$ Diagnosis depends on special investigations including examination of the expressed prostatic secretion (EPS) and other investigations. Definite prostatic tenderness or urethritis contraindicate prostatic massage.

\section{Examination of the expressed prostatic secretion (EPS)}

Prostatic secretion forms $15-30 \%$ of the volume of the human ejaculate. ${ }^{9}$ Rectal massage of the prostate produces $0.1-1.0 \mathrm{ml}$ of EPS which has been described as reasonably uncontaminated. ${ }^{9}$ This lack of contamination is arguable and the patient should void before prostatic massage to reduce contamination by urethral micro-organisms, but the EPS may be more susceptible to contamination by urethral flora than urine. ${ }^{10}$ A further problem is that the inflammatory process may block ducts thus preventing the outflow of secretion from the very focus one wishes to evaluate.

Microscopic examination of the EPS and estimation of the numbers of polymorphonuclear cells (PMN) was a time honoured method of assessing prostatitis, but the upper limit of normal was often unclear. ${ }^{11}$ Clumping or aggregation of the PMN into

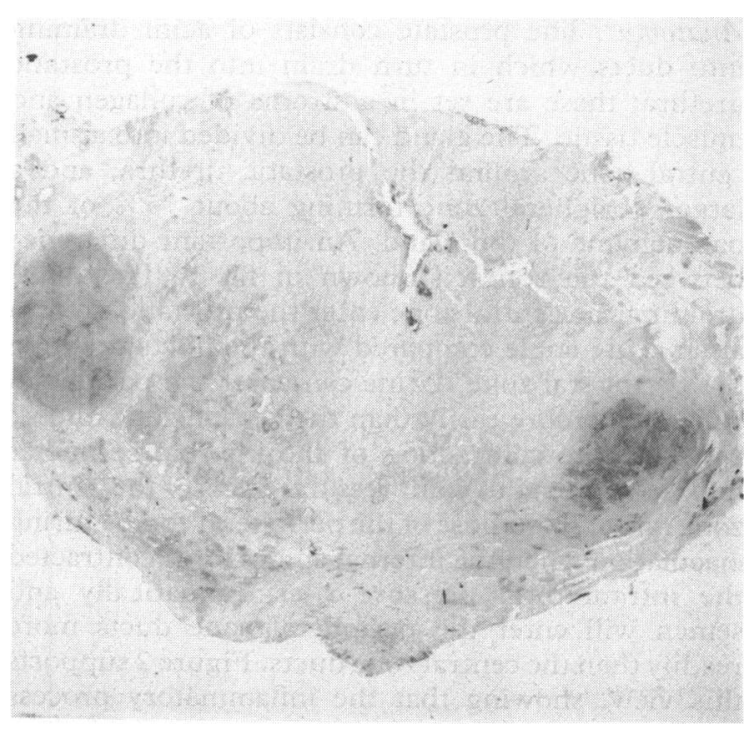

Figure 2 Transverse section of prostate stained by haematoxylin and eosin showing white cell infiltration (dark areas) and microabscesses in the peripheral zonemagnification $\times 3$.

(Courtesy of Dr C M Parkinson). 


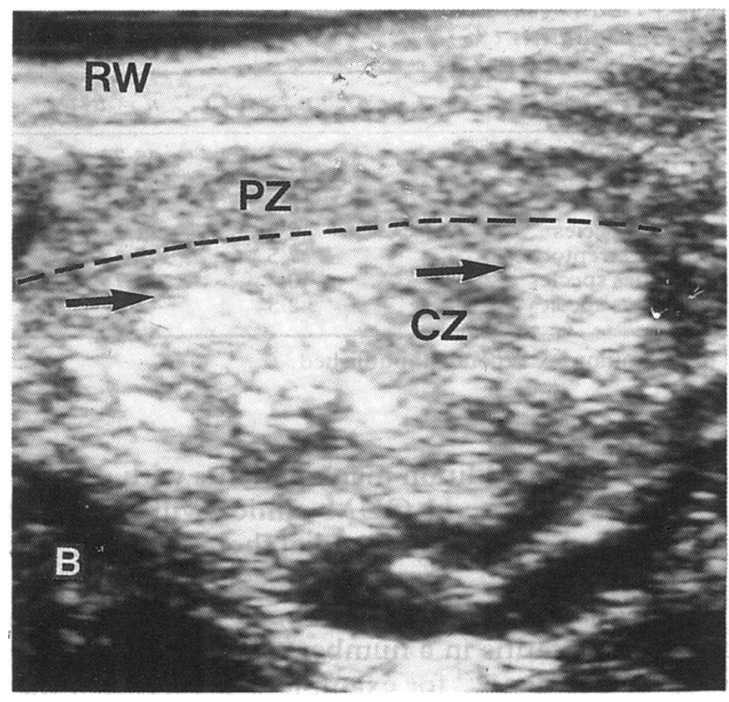

Figure 3 Sagittal section of prostate gland on transrectal ultrasound.

$C Z$, arrows-echogenic foci. $P Z$-peripheral zone, normal -..-division between central and peripheral zones. $B$-bladder

$R W$-anterior rectal wall.

(Courtesy of Dr D Richards).

groups, and a reduction in the number of lecithin bodies also indicate inflammation. An additional finding is macrophages containing fat droplets, sometimes called oval fat bodies. ${ }^{11}$ This method of simple microscopy was unreliable and no good reproducibility data have been published.

The whole understanding of prostatitis improved when Meares and Stamey ${ }^{1213}$ described their technique for examining the EPS and comparing the findings with those in the urine. They collected the first $5-10 \mathrm{ml}$ of urine which they called voided bladder urine 1 or VB1 (it might also be called first catch urine). The patient then voided about $200 \mathrm{ml}$ urine and a second 5-10 $\mathrm{ml}$ sample was collectedvoided bladder urine 2 (VB2) or midstream urine. The prostate was massaged and the EPS collected. Finally the first $5-10 \mathrm{ml}$ urine passed after prostatic massage was obtained-voided bladder urine 3 (VB3) or post prostatic massage urine.

Initially emphasis was placed on quantitative microbiological examination using techniques which quantify small numbers of organisms. A high bacterial count in VB1 with low counts in the other samples indicated acute bacterial urethritis. A high count in VB2 and VB3 in the presence of normal findings in the other specimens indicated an upper urinary tract infection. A high bacterial count in the EPS and VB3 with normal findings in VB1 and VB2 indicated bacterial prostatitis. The findings are not always clearcut in clinical practice but the technique is a great improvement on simple assessment of the EPS, and can always be repeated if ambiguous results are obtained.

As part of the technique, counting the number of PMN in a drop of EPS on a microscope slide may give an indication of inflammation. An upper limit of normal of $15 \mathrm{PMN}$ per high power field (hpf) is frequently quoted, ${ }^{14}$ but sometimes without any indication if this is a fresh wet preparation, a fixed stained smear, or the magnification. Use of a counting chamber may give a more accurate indication of cellular reaction, and an upper limit of normal of $1000 \mathrm{PMN} / \mathrm{mm}^{3}$ has been suggested. ${ }^{7}$ This approximates to $15 \mathrm{PMN} / \mathrm{hpf}$ (using a $\times 40$ objective) and a fresh wet preparation on a slide.

As shown in table 1, Drach et $a l^{15}$ proposed the classification of chronic prostatitis into chronic bacterial prostatitis, chronic non-bacterial prostatitis, and prostatodynia on the basis of this technique. In chronic non-bacterial prostatitis a cellular reaction without bacterial pathogens is found in the EPS and VB3. In prostatodynia there are clinical features suggesting prostatitis but no pathogens, no cellular reaction, and no other cause for the symptoms.

Simmons and Thin ${ }^{16}$ used this technique to study patients in whom urethritis had been excluded by early morning examination, ${ }^{17}$ and had normal findings in a midstream urine sample. They found no advantage in full microbiological examination of VB1 and VB2 samples, and suggested that macroscopic examination of these samples is sufficient after preliminary screening in this manner in a genitourinary medicine (GUM) clinic.

The application of Stamey's technique and the interpretation of the findings were reviewed by Krieger and McGonagle. ${ }^{6}$ They concluded that attention to technique was important especially when non pathogenic bacteria such as coagulase negative staphyloccoci were isolated. They considered that these organisms could be ignored especially in the absence of a leucocyte reaction in the EPS. Close liason between clinician and the laboratory are important but this is well recognised by genitourinary medicine physicians. Stamey's technique has been used by other groups as the baseline with which to compare other methods. ${ }^{18}$

The $\mathrm{pH}$ of the EPS has been a subject of considerable study. Early work centred on dogs but they were subsequently found to have a lower $\mathrm{pH}$ than man. ${ }^{19}$ The $\mathrm{pH}$ of the EPS obtained from normal men still appears to be unclear with figures ranging from 6.5 to $8 \cdot 0 .{ }^{14}{ }^{20}$ The $\mathrm{pH}$ usually rises in prostatitis and there is more agreement on these findings with a mean of 8.32 and standard deviation of 0.07 according to one authority, ${ }^{14}$ and up to $8 \cdot 2$ according to another. ${ }^{20}$ Individual variation can be considerable (table 2). An additional problem is contamination of EPS by semen which has a higher $\mathrm{pH}$. It appears that the $\mathrm{pH}$ 
Table 2 EPS pH and cellular reaction

\begin{tabular}{lrlll}
\hline$p H$ & $\begin{array}{l}\text { EPS cell } \\
\text { count range }\end{array}$ & $\begin{array}{l}\text { PMN/cu mm } \\
\text { median }\end{array}$ & $\begin{array}{l}\text { Cell estimation } \\
\text { range }\end{array}$ & $\begin{array}{l}\text { PMN/hpf } \\
\text { median }\end{array}$ \\
\hline $6 \cdot 8$ & $10-5000$ & 390 & $1-3$ & $2 \cdot 0$ \\
$7 \cdot 1$ & $150-5000$ & 620 & $1-5$ & $2 \cdot 5$ \\
$7 \cdot 4$ & $25-5000$ & 775 & $1-18$ & $1 \cdot 2$ \\
$7 \cdot 7$ & $360-5000$ & 600 & $1-12$ & $1 \cdot 5$ \\
$8 \cdot 0$ & $60-5000$ & 5000 & $1-24$ & $5 \cdot 4$ \\
\hline
\end{tabular}

Thin \& Simmons (unpublished).

may be helpful, especially if a rapid decision is required, but needs to be considered with all the other findings.

\section{Microbiological investigation}

Microscopy should be undertaken immediately the EPS is obtained and cultures should be set up as soon as possible afterwards. The organisms commonly isolated from the EPS in chronic bacterial prostatitis include Escherchia coli, enterococci, Pseudomonas aeruginosa, klebsiella species, and Proteus mirabilis, (table 3). ${ }^{6{ }^{12-14}}$ The cellular reaction associated with these organisms is shown in table 4.

Staphylococcus aureus has been documented as a cause, usually as a hospital acquired, catheter associated infection. ${ }^{14}$ The role of other aerobic organisms such as Staphylococcus epidermidis, micrococci, streptococci, and diphtheroids is unclear but they are probably commensals rather than pathogens. ${ }^{614}$

There appear to be very few reports on anaerobic bacteria in prostitatis. Bacteriodes species and peptococci have been isolated from patients with prostatitis though their role is unclear ${ }^{18}$ (and Wood, personal communication). Any serious study on the diagnosis of prostatitis should include cultural techniques for these organisms since they may be associated with a cellular reaction similar to that of established aerobic pathogens (table 4).

The role of Chlamydia trachomatis is not yet established. Though Poletti et $a l^{21}$ isolated $C$ trachomatis from 10 of 30 samples of prostatic tissue obtained by transrectal needle biopsy, they were cautious in ascribing an aetiological role to the organism. In an editorial accompanying this report Schachter ${ }^{22}$ also advised caution in interpreting these findings, noting that the entry criteria for this study included the presence of chlamydial urethritis. In another study of specimens obtained by percutaneous transperineal needle biopsy of the prostate, $C$ trachomatis was not detected by culture or immunofluorescent antigen detection in any of 50 patients with non-bacterial prostatitis. ${ }^{23}$ It was concluded that there was no evidence of direct implication of $C$ trachomatis in chronic non-bacterial prostatitis, though the possibility of an aetiological role for this organism earlier in the course of the disease could not
Table 3 Pathogens isolated from patients with chronic bacterial prostatitis (\%)

\begin{tabular}{lll}
\hline & $n=40$ & $n=84 \dagger$ \\
\hline Escherichia coli & $45 \cdot 0$ & $35 \cdot 7$ \\
Enterococci & $30 \cdot 0$ & $38 \cdot 1$ \\
Proteus mirabilis & $12 \cdot 5$ & $15 \cdot 5$ \\
Klebsiella species & $2 \cdot 5$ & $1 \cdot 2$ \\
Anaerobic streptococci & $7 \cdot 5$ & $2 \cdot 4$ \\
Bacterioides species & 0 & $4 \cdot 7$ \\
Peptococcus species & $2 \cdot 5$ & $2 \cdot 4$ \\
\hline
\end{tabular}

†Thin, Simmons \& Wood-unpublished.

be excluded. In addition many patients with chronic prostatitis who attend GUM clinics will have had multiple courses of antichlamdial therapy before this diagnosis is made.

Ureaplasma urealyticum has been implicated as a cause of prostatitis in a number of reports from one group in Germany $;{ }^{24}$ for example $U$ urealyticum was isolated from $83(13.7 \%)$ of 597 patients with chronic prostatitis. No other workers have reported similar findings.

\section{Other diagnostic techniques}

Semen analysis There are few reports on the cellular reaction and microbiological culture of semen in chronic prostatitis. In one study of 12 men it was reported that culture of semen was reliable in the diagnosis of bacterial prostatitis. ${ }^{25}$ One practical difficulty of this apparently simple technique is that of obtaining samples of semen for analysis at the appropriate time.

Immune response In bacterial prostatitis immunoglobulins specific for the infecting organism can be detected in serum and EPS. They appear to be short lived but antigen specific IgA and IgG in the EPS may be helpful in diagnosis, ${ }^{14}{ }^{26}$ though rarely used in practice.

Prostatic ultrasound The first studies reporting that transrectal ultrasound scanning (TRUS) of the prostate can reliably indicate prostatitis ${ }^{2}$ were extended by the same group. ${ }^{27}$ Seven features of TRUS associated with prostatitis have been described and correlated with an EPS PMN cell count of $600 / \mathrm{mm}^{3}$ and a VB3 PMN count of $100 / \mathrm{mm}^{3}{ }^{28}$ TRUS is very

Table 4 Bacterial pathogens and cell counts

\begin{tabular}{lcl}
\hline Organism & No studied & $\begin{array}{l}\text { Median } \\
\text { cell count }\end{array}$ \\
\hline Escherichia coli & 17 & 1150 \\
Enterococcus & 17 & 5000 \\
Proteus species & 12 & 1190 \\
Klebsiella species & 2 & 3500 \\
Anaerobes & 9 & 1836 \\
\hline
\end{tabular}

Thin unpublished.

Thin \& Simmons. ${ }^{8}$ 
useful in the diagnosis of chronic prostatitis, but gives no indication of the cause. TRUS also has a valuable role in the diagnosis and localisation of prostatic abscess. ${ }^{29}$ TRUS allows guided needle aspiration to obtain material for culture. ${ }^{1823}$ Percutaneous transperineal needle biopsy minimises the risk of bacterial contamination and and maximises the likelihood of obtaining samples from infected foci which is crucial for the diagnosis of a focal infection. Contamination from the perineal skin may be a problem but can be overcome by preliminary skin sampling and careful technique. ${ }^{18}$ Ultrasound guided needle biopsy and sampling is clearly a more reliable technique than blind sampling of the prostate. ${ }^{18}$

Other imaging techniques Computed tomography cannot identify intrinsic prostatic disease so is of no value in the diagnosis of prostatitis. ${ }^{30}$ Magnetic resonance imaging (MRI) cannot distinguish between benign and malignant processes within the prostate and appears to offer no advantage over TRUS. ${ }^{30} 31$ Magnetic resonance spectroscopy needs further development but at present appears unlikely to be of value in the diagnosis of prostatitis.

There is some epidemiological evidence suggesting that some radionuclides are concentrated in the prostate and may have a role in the aetiology of prostatic cancer, though other factors may also be involved. ${ }^{32}{ }^{33}$ No reports have been found in the literature of the use of isotopes in the diagnosis of prostatic disease.

\section{Conclusion}

The clinical features that indicate prostatitis include perineal ache and penile tip pain in association with other urinary tract symptoms. Definite localised tenderness is a rare but helpful clinical sign. Diagnosis usually rests on special investigations. Stamey's technique $^{12}{ }^{13}$ of investigation of VB1, VB2, EPS, and VB3 remains the corner stone of diagnosis, ${ }^{18}$ for it demonstrates the presence of prostatitis and may provide a microbiological cause. TRUS is clearly useful for it is quick, convenient and relatively cheap (compared with techniques such as MRI). It does not provide any aetiological information, but if there are sufficient local features guided needle aspiration may provide more informaton than the EPS.

Address for correspondence: Dr R N Thin, Department of Genitourinary Medicine, St Thomas's Hospital, London SE1 7EH, UK

1 Blacklock NJ. The prostate; surgical anatomy. In: Chisholm GD, Fair WR, eds. Scientific Foundations of Urology, 3rd ed, London: Heinemann, 1990:340-50.

2 Peeling WB, Griffith GJ. Imaging of the prostate by ultrasound. $J$ Urol 1984;132:217-24.

3 Sutor DJ, Wooley SE. The crystalline composition of prostatic calculi. Br J Urol 1974;46:533-41.

4 Ramirez CT, Ruiz JA, Gomez AZ, et al. A crystallographic study of prostatic calculi. J Urol 1980;124:840-8.
5 Kirby RS, Lowe D, Bultitude MI, Shuttleworth KED. Intraprostatic urinary reflux: an aetiological factor in abacterial prostatitis. Br J Urol 1982;54:729-31.

6 Krieger JN, McGonagle LA. Diagnostic considerations and interpretation of microbiological findings for evaluation of chronic prostatitis. J Clin Microbiol 1989;27:2240-4.

7 Anderson RU, Weller C. Prostatic secretion leukocyte studies in non-bacterial prostatitis (prostatosis). J Urol 1979;121:292-4.

8 Thin RN, Simmons PD. Chronic bacterial and non-bacterial prostatitis. Br J Urol 1983;55:513-8.

9 Daniels GF, Grayhack JT. Physiology of prostatic secretions. In: Chisholm GD, Fair WR, eds. Scientific Foundations of Urology, 3rd ed. London: Heinemann, 1990:351-8.

10 Fowler JE, Mariano M. Difficulties in quantitating the contribution of urethral bacteria to prostatic fluid and seminal fluid cultures. J Urol 1984;132:471-3.

11 Oates JK. Prostatitis. Br J Hosp Med 1969:556-61.

12 Meares EM, Stamey TA. Bacteriologic localisation patterns in bacterial prostatitis and urethritis. Invest Urol 1968;5: 492-518.

13 Stamey TA. Prostatitis. JR Soc Med 1981;74:22-40.

14 Meares EM. Prostatitis. In: Chisholm GD, Fair WR, eds. Scientific Foundations of Urology, 3rd ed. London: Heinemann, 1990:373-8.

15 Drach GW, Meares EM, Fair WR, Stamey TA. Classification of benign disease associated with prostatic pain: prostatitis or prostatodynia? J Urol 1978;120:266.

16 Simmons PD, Thin RN. A method for recognising non-bacterial prostatitis: preliminary observations. Br J of Venereal Dis 1983;59:306-10.

17 Simmons PD. Evaluation of the early morning smear investigation. Br J Venereal Dis 1978;54:128-9.

18 Doble A, Thomas BJ, Furr PM, et al. A search for infectious agents in chronic abacterial prostatitis using ultrasound guided biopsy. Br J Urol 1989;64:297-301.

19 Fair WR, Cordonnier JJ. The pH of prostatic fluid: a re-appraisal and therapeutic implications. $J$ Urol 1978;120:695-8.

20 Colleen S, Mardh P-A. Prostatitis. In: Holmes KK, Mardh P-A, Sparling PF, Wiesner PJ, eds. Sexually Transmitted Diseases, 2nd ed, New York; McGraw-Hill, 1989:653-61.

21 Poletti F, Medici MC, Alinovi A, et al. Isolation of Chlamydia trachomatis from the prostatic cells in patients affected by nonacute abacterial prostatitis. J Urol 1985;134:291-3.

22 Schachter J. Is Chlamydia trachomatis a cause of prostatitis? J Urol 1985;134:711.

23 Doble A, Thomas BJ, Walker MM, Harris JRW, Witherow RO'N, Taylor-Robinson D. The role of Chlamydia trachomatis in chronic abacterial urethritis: a study using ultrasound guided biopsy. $J$ Urol 1989;141:332-3.

24 Brunner $H$, Weidner W, Schiefer H-G. Studies on the role of Ureaplasma urealyticum and Mycoplasma hominis in prostatitis. $J$ Infect Dis 1983;147:807-13.

25 Mobley DF. Semen cultures in the diagnosis of bacterial prostatitis. J Urol 1975;114:83-5.

26 Shortliffe LMD, Stamey TA. The immunologic characterisation of bacterial prostatitis caused by enterobacteriaceae. In: Brunner H, Krause W, Rothauge CF, Weidner W, eds. Chronic Prostatitis: Clinical, Microbiological, Cytological and Immunological Aspects of Inflammation. Stuttgart: Schattauer, 1985:107-12.

27 Griffiths GJ, Crooks AJR, Roberts EE, et al. Ultrasonic appearances associated with prostatic inflammation. Clin Radiol 1984;35:343-5.

28 Doble A, Carter S St C. Ultrasonographic findings in prostatitis. Urol Clin North Am 1989;16:763-72.

29 Cytron S, Weinberger M, Pitlik SD, Servadio C. Value of transrectal ultrasonography for diagnosis and treatment of prostatic abscess. Urology 1988;32:454-8.

30 Rifkin MD, Serhouni EA, Gatsonis CA, et al. Comparison of magnetic resonance imaging and ultrasonography in staging early prostatic cancer. NEng J Med 1990;323:621-6.

31 Spicer KM. The role of magnetic resonance imaging (MRI) in urology. In: Rous SN, ed. Urology Annual, Vol 4. East Norwalk, Conn USA: Appleton Lang; 1990:207-53.

32 Beral V, Inskip H, Fraser P, Booth M, Coleman D, Rose G. Mortality of employees of the United Kingdom Atomic Energy Authority. Br Med J 1985;291:440-7.

33 Evans HJ. Leukaemia and radiation; the Gardner Report. Nature 1990;345:16-7.

Accepted for publication 15 April 1991 